\title{
Combined structural and electrical characterization of zirconia-based thin films for energy applications
}

\author{
Y. Mansilla ${ }^{1}$, M. Arce ${ }^{1,2}$, C. E. Jiménez ${ }^{2}$, J. Basbus ${ }^{1}$, D. M. Többens ${ }^{2}$, A. Serquis ${ }^{1}$ \\ ${ }^{1}$ INN-CNEA-CONICET, Av. Bustillo 9500, S. C. de Bariloche, Rio Negro, 8400, Argentina, ${ }^{2}$ Helmholtz-Zentrum Berlin für \\ Materialien und Energie, Albert-Einstein-Str.15, 12489, Berlin, Germany.
}

yanet.mansilla@cab.cnea.gov.ar

Zirconia based materials possess a unique set of attractive properties, which are responsible for the many applications in which they are used [1]. Some of these involve the use of thin films, whose properties are highly dependent on synthesis and deposition methods. Major changes in the $\mathrm{Zr}-\mathrm{O}$ phase diagram, thus in material properties, occur when the crystallite size is reduced down to the nanoscale. A good example is that cubic or tetragonal phases, that have better mechanical properties than the monoclinic phase, can be retained in nanocrystalline zirconia [2,3]. The addition of yttria to zirconia can also lead to the stabilization of the high symmetry phases, producing the well-known yttria stabilized zirconia (YSZ). YSZ is the most widely used electrolyte in solid oxide fuel cells (SOFC) due to its high and pure ionic conductivity above $800{ }^{\circ} \mathrm{C}$. However, such high operation temperatures result in high degradation rate for the SOFC, which increases the cost of this technology. Different strategies have been proposed to lower the SOFC operating temperature, being one appealing approach to employ dense thin-film based electrolytes [4].

For this work we synthetized $\mathrm{ZrO}_{2}$ and $8 \mathrm{YSZ}$ (zirconia stabilized with $8 \% \mathrm{~mol}$ of yttria) by the sol-gel method and deposited thin films by dip-coating on glass substrates. The thin film crystallization process was studied in situ by grazing incidence X-Ray diffraction (GIXRD) at the KMC-2 beamline of the BESSY II synchrotron light source of Berlin by varying temperature between 300 and $800{ }^{\circ} \mathrm{C}$ in steps of $20^{\circ} \mathrm{C}$, coupled with electrical measurements using the 2-probe method.
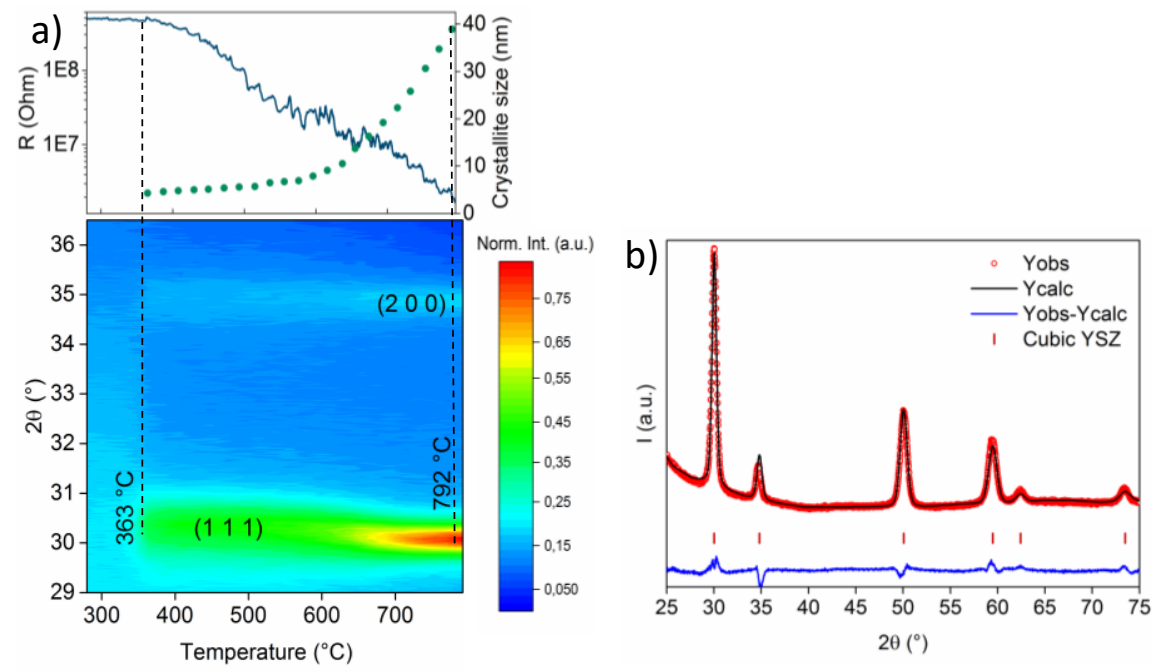

Figure 1. YSZ thin film: a) Resistance, crystallite size and diffracted intensities vs. temperature, reflexions (2 000$)$ and ( 100$)$ correspond to the cubic phase, and b) Rietveld refinement on a post-treated sample at room temperature. Radiation energy: $8 \mathrm{KeV}$.

Synthesized thin films have thicknesses between 100 and $200 \mathrm{~nm}$. The in situ study on YSZ, presented as example in Figure 1, allowed us to determine how the nano crystallite size of the thin film evolved from $4 \mathrm{~nm}$ at $363{ }^{\circ} \mathrm{C}$ to $40 \mathrm{~nm}$ at $792{ }^{\circ} \mathrm{C}$. The simultaneously measured resistivity enabled us to correlate temperature dependant transport and structural properties of these films. In both $\mathrm{ZrO}_{2}$ and $\mathrm{YSZ}$ thin films, highly symmetric phases (tetragonal and cubic, respectively) are retained at high temperature and after cooling.

[1] Chen, Y.W., Moussi, J., Drury, J. \& Wataha, J. (2016). Exp. Review of Medical Devices. $10,945$.

[2] Garvie, R. C. (1965). J. Phis.Chem. 69, 1238.

[3] Butler, E.P. (1985). Mater. Sci. Technol. 1, 417.

[4] Tarancon, E.P. (2009). Progress in Materials Science. 4, 1130.

Keywords: Thin films; Zirconia; YSZ; Electrical conductivity; metastable phase. 